\title{
Arahan Pengembangan Pariwisata Heritage Terpadu di Kota Madiun
}

\author{
Burhanudin Fahmi Fathoni \\ Departemen Perencanaan Wilayah dan Kota, Fakultas Teknik Sipil dan Perencanaan, Institut Teknologi \\ Sepuluh Nopember (ITS) \\ e-mail: haryo.its@gmail.com
}

\begin{abstract}
Abstrak-Kota Madiun merupakan kota yang memiliki peninggalan bangunan cagar budaya baik dari era Kolonial dan peninggalan era Mataraman, yang tersebar di 3 kecamatan yaitu kecamatan Taman, Manguharjo, dan Kartoharjo. Didalam ketiga kecamatan tersebut memiliki potensi, baik di lihat dari artefak yang memiliki nilai sejarah yang tinggi serta budaya kota madiun yang mengakar. Dalam potensi potensi tersebut terdapat permasalahan di mana tidak adanya integrasi dari setiap kawasan cagarbudaya. Integrasi disini digunakan sebagai upaya menjadikan kawasan heritage menjadi kawasan heritage tourism yang terpadu dan saling berkesinambungan. Di tinjau dari peraturan daerah yang belum berjalan dengan ideal dengan memanfaatkan potensi kawasan heritage yang memiliki ciri khas masing masing. Penelitian ini memiliki 3 tahapan analisis. dimana tahap pertama yaitu mengidentifikasi Potensi fisik dan non fisik yang dimiliki kawasan Heritage dengan menggunakan analisis descriptive. Tahap kedua adalah menganalisis faktor-faktor yang mempengaruhi pengembangan kawasan heritage tourism di kota Madiun dengan menggunakan analisis dhelfie. dan tahap ketiga menggunakan analisis triangulasi. Hasil penelitian menunjukan bahwa Kota Madiun memiliki potensi yang dapat dikembangkan menjadi salah satu destinasi wisata budaya. Arahan pengembangan kawasan dan pengintegrasian kawasan ditunjang dengan analisis area, serta faktor pendukung pengembangan kawasan heritage kota madiun yang di bedakan menjadi dua cluster, yaitu cluster era kolonial dan cluster Islam. Sementara output dalam analisis dibedakan menjadi 2, yakni arahan makro dan mikro. Arahan pengembangan kawasan sebagai wisata heritage secara mikro adalah pembagian area pengembangan kegiatan wisata menjadi 3 area, antara lain area inti, area pendukung langsung, dan area pendukung tidak langsung. Hasil analisis area tersebut, area inti pada cluster era kolonial berada pada koridor jalan pahlawan dengan patung kolonel mahardi beserta rumah kapiten cina. dan pada cluster era islam berada pada 2 masjid kuno yaitu masjid taman dengan masjid Kuncen. Sementara arahan pengembangan makro merupakan arahan umum untuk kedua cluster sehingga nantinya akan di integrasi menjadi satu rangkaian heritage tourism.
\end{abstract}

\section{PENDAHULUAN}

$\mathrm{U}^{\mathrm{N}}$ NITED Nations World Tourism Organization (UNWTO) pada tahun 2005 mencatat bahwa kunjungan ke obyek wisata warisan budaya dan sejarah telah menjadi salah satu kegiatan wisata yang tercepat pertumbuhannya [1]. Dua jenis kegiatan wisata yang erat hubungannya dengan warisan budaya dan peninggalan sejarah adalah cultural tourism (wisata budaya) dan Heritage tourism (wisata ke situs-situs warisan atau pusaka). Poria et al. (2006)[2] mendefinisikan Heritage tourism sebagai setiap kunjungan ke situs warisan budaya, alam maupun peninggalan sejarah, terlepas dari motivasi dan persepsi pengunjung pada atribut situs tersebut. Sesuai dengan definisi Cagar Budaya dalam UU Nomer 11 tahun 2010 tentang Cagar Budaya, definisi Cagar Budaya disebutkan sebagai warisan budaya bersifat kebendaan berupa Benda Cagar Budaya, Bangunan Cagar Budaya, Struktur Cagar Budaya, Situs Cagar Budaya, dan Kawasan Cagar Budaya di darat dan/atau di air yang perlu dilestarikan keberadaannya karena memiliki nilai penting bagi sejarah, ilmu pengetahuan, pendidikan, agama, dan/atau kebudayaan melalui proses penetapan.

Pada tahun 1920-an, Madiun mengalami proses transformasi menjadi wilayah perkembangan pembangunan yang pesat dari berbagai versi bangunan arsitektural Belanda kontemporer dan berbagai tema perencanaan kota yang diantaranya ada perpaduan dengan elemen tradisi regional wilayah tersebut (Groll,1988). Banyak peninggalan bangunan Era Kolonial seperti : Rumah Kapitan China, Jl. Kol. Marhadi Kota Madiun (woming Kapitan China); Gereja Cornelius, jl.Pahlawan Kota Madiun; Kantor Pemerintah Kota Madiun, Jl. Pahlawan Kota Madiun (gementee huis); Kantor Bakorwil (karesidenan), Jl. Pahlawan Kota Madiun (residence kantooren); Bosbow, Jl. Diponegoro Kota Madiun ( gedung OSVIA); PG. Rejoagung di Patihan; Masjid Kuno Taman di kecamatan Taman; Masjid Kuncen di Josenan, arsip Kompas Madya HVM.[2]

Menurut Perda RTRW Kota Madiun tahun 2010-2030 mengenai kawasan Strategis. Bahwa kota Madiun memiliki potensi Kawasan Pariwisata Strategis Sosial Budaya dimana banyaknya peninggalan bangunan-bangunan era Kolonial. Di antaranya PG. Rejoagung, Gedung Bakorwil, Gedung Gemente Rumah Kapiten Cina, Monumen Kolonel Marhadi yang kesemuanya berada di kecamatan Manguharjo. Serta ada bangunan Cagar budaya seperti Masjid Kuno Taman, dan Masjid Kuncen di Kecamatan Kuncen. Dan di kecamatan Kartoharjo terdapat Bosbow di jalan Diponegoro.[3]

Mengenai Kawasan Strategis Sosial Budaya, Bahwa banyaknya bangunan-bangunan Cagar Budaya yang tidak terawat. seperti kawasan Bosbow (gedung OSVIA) dimana bangunannya sudah tidak kokoh dan banyak yang rapuh dan harus adanya upaya untuk menjaga kelestariannya serta melestarikan aset-aset budaya peninggalan sejarah di Kota Madiun. Yang berpotensi sebagai kawasan Pariwisata Heritage Tourism. serta beberapa bangunan Cagar Budaya yang berpotensi sebagai kawasan Pariwisata dialih fungsikan dan belum terkelola dengan baik. Pemerintah Kota Madiun sendiri belum berupaya optimal dalam upaya mengembangkan kawasan Pariwisata Cagar Budaya, (wawancara dengan Wija 
Ketua HVM pecinta banguan Heritage di kota Madiun, 2015).[4]

Kota Madiun memiliki potensi cukup besar dalam mengoptimalkan Pariwisata Heritage.Seperti PG. Rejoagung Baru yang didirikan tahun 1894 yang merupakan penyuplai gula terbesar di jawatimur kala itu. pabrik yang masih menjaga nilai arsitektur tempo dulu ini ditetapkan pada perda RTRW kota Madiun sebagai kawasan strategis Sosial Budaya. Salah satu bangunan kolonial Belanda di Kota Madiun yang masih mempertahankan bentuk asli dan masih berfungsi dengan baik adalah rumah dinas Kantor Badan Koordinasi Wilayah (Bakorwil). Rumah dinas Bakorwil terletak di Pusat kota, yaitu Jalan Pahlawan dan menjadi salah satu bangunan tertua peninggalan kolonial Belanda di kawasan tersebut. Bangunan ini dibangun sekitar tahun 1850-an dan difungsikan hingga sekarang. dan juga Masjid kuno Kuncen, Masjid tertua di Madiun sebagai bukti lahirnya nama Madiun dan para pendiri kota Madiun serta berkuasanya kerajaan era Mataraman di Madiun. masjid Kuno Kuncen dibangun pada tahun 1575 atau pada akhir abad XVI.[5] Perlu adanya integrasi kawasan heritage di kota Madiun di lihat dari karakteristik non fisik setiap bangunan cagar budaya yang saling berkaitan. Sehingga memberika travel experience bagi wisatawan yang mengunjungi kawasa heritage. Di mana sejarah bangunan era colonial yang terhubung dengan kebesaran kerajaan era Mataraman di kota Madiun sehingga perlu adanya langkah integrasi kawasan. Lokasi dari setiap kawasan Heritage tersebut berada tersebar di 3 kecamatan yaitu kecamatan Manguharjo, Kecamatan Taman, Kecamatan Kartoharjo. Di kecamatan Manguharjo terdapat PG. Rejo Agung Baru, Gedung Bakorwil, Rumah Kapiten Cina serta Monumen Kolonel Marhadi. Di kecamatan Kartoharjo terdapat bangunan Bosbow. Di kecamatan Taman terdapat Masjid Kuno Taman serta Masjid Kuno Kuncen. Namun dari semua kawasan pariwisata heritage tersebut tidak terintegrasi dengan baik dapat dilihat dari kurangnya jaringan Transportasi yang menghubungkan kawasa heritage sehingga kurang berkembang dengan optimal, Akomodasi di kawasan pariwisata yang kurang memadai serta kurangnya upaya pemerintah dalam proses pengembangan pariwisata heritage yang sudah di tetap kan pada perda RTRW sebagai kawasan potensi pariwisata.[6]

\section{II.METODE PENELITIAN}

\section{A. Jenis Penelitian}

Penelitian ini menggunakan pendekatan kualitatif. Penelitian kualitatif adalah riset yang bersifat deskriptif di mana proses dan makna (perspektif subyek) lebih ditonjolkan dalam penelitian. Landasan teori dimanfaatkan sebagai pemandu agar fokus penelitian sesuai dengan fakta di lapangan.

\section{B. Variabel Penelitian}

Berdasarkan kajian literature yang telah dilakukan, didapatkan beberapa variabel yang mendukung dalam penelitian ini guna mencapai sasaran dalam penelitian. Variabel yang digunakan dalam penelitian ini merupakan hasil dari sintesa teori pada bab kajian pustaka yang dalam hal ini sintesa teori sudah selaras dengan ruang lingkup penelitian. Dalam penelitian ini variabel yang digunakan antara lain :
- Kelangkaan bangunan cagar budaya

- Nilai sejarah Kawasan Heritage

- Estetika Kawasan Heritage

- Memiliki pengaruh terhadap lingkungan sekitar

- Nilai kebudayaan masyarakat di kawasan heritage

- Pemgetahuan masyaakat mengenai kawasan heritage

- Jenis kegiatan masyarakat di sekitar kawasan heritage

- Jumlah komunitas local yang ada di sekitar kawasan heritage

- Kebijakan pemerintah mengenai pengembangan kawasan heritage

- Keterlibatan masyarakat di kawasan heritage dalam proses perencanaan kawasan

- Keberadaan artefak

- Kondisi Kawasan Heritage

- Keberadaan kebudayaan hidup

- Ketersediaan akomodasi

- Ketersediaan fasilitas pendukung wisata

- Ketersediaan moda transportasi menuju kawasan heritage

- Fasilitas transportasi

- Tersedianya jaringan jalan

\section{Mengidentifikasi Potensi fisik dan non fisik yang dimiliki kawasan Heritage}

Untuk mencapai sasaran ini, digunakan teknik analisis deskriptif kualitatif dengan metode Analisis Descriptive Metode ini digunakan untuk menggambarkan fenomena yang diteliti secara sistematis, faktual, dan akurat. Dengan menggunakan metode ini, obyek penelitian dianalisis dalam bentuk penjelasan ataupun pengertian.

Proses analisis Descriptive merupakan proses analisis data secara kualitatif dengan menggunakan data yang diperoleh dari data sekunder yang dijelaskan secara deskriptif dan normatif yang disesuaikan dengan kondisi eksisting obyek penelitian di kota Madiun dengan menggunakan variabel komponen pariwisata. Untuk mengidentifikasi data primer yang dikolaborasikan. Data primer tersebut berupa karakteristik individu/obyek, kelompok, dan komunitas. Dari kedua analisis tersebut akan didapatkan kesesuaian variabel antara data primer dan data sekunder..

\section{D.Menganalisis faktor-faktor yang mempengaruhi pengembangan kawasan heritage tourism di kota Madiun}

Untuk mengetahui faktor penyebab pengembangan di kawasan penelitian, digunakan Analisis Dhelpi. Dengan menggunakan variable perkembangan kawasan. Analisis dilakukan dengan mendiskusikan variabel yang didapat dari hasil kajian pustaka dengan kondisi eksisting di kawasan penelitian. Setelah didapatkan faktor yang menyebabkan perkembangan kawasan, dilanjutkan pada tahap analisis berikutnya. Tahapan kedua berupa fiksasi faktor yang dihasilkan dari analisis tahap pertama dengan menggunakan analisis Stakeholder.

Langkah selanjutnya berupa pemilihan responden yang telah ditetapkan dari hasil analisis stakeholders terkait. Responden yang dipilih merupakan responden yang memiliki hubungan, kapasitas, dan pengetahuan tentang KCB. Metode ini dilakukan dengan wawancara kepada responden untuk menilai variabel-variabel penelitian berdasarkan bidang keahlian dan pemahaman mengenai kawasan penelitian. Setelah didapatkan 
faktor-faktor penyebab penurunan vitalitas dari stakeholder terkait, akan dilanjutkan dengan teknik analisis Delphi sebagai fiksasi faktor-faktor yang telah didapatkan. Teknik analisis Delphi adalah suatu usaha untuk memperoleh konsensus grup secara kontinu, sehingga diperoleh konvergansi opini. Pada tahap ini dilakukan analisis terhadap faktor penyebab penurunan vitalitas yang dihasilkan dari wawancara pada responden terkait telah mencapai konsensus. Bila belum mencapai konsensus, akan dilakukan iterasi hingga dihasilkan faktor-faktor yang konsensus antar responden terkait. Hasil dari analisis Delphi adalah faktor-faktor penyebab penurunan vitalitas cagar budaya.

\section{E. Menentukan arahan integrasi kawasan pariwisata heritage di kota Madiun}

Untuk menghasilkan rumusan arahan integrase terpadu kawasan heritage di Madiun, akan menggunakan analisis triangulasi dengan tujuan untuk menghasilkan rumusan tunggal arahan integrasi dari sudut pandang para ahli yang berbeda. Teknik traingulasi merupakan suatu teknik pengumpulan data yang bersifat menggabungkan dari berbagai teknik pengumpulan data dan sumber data yang telah ada.

Pada dasarnya, analisis triangulasi menggunakan lebih dari 1 sumber data yang berbeda yang nantinya akan dijadikan sebagai pertimbangan dalam perumusan arahan integrasi di kawasan penelitian sebagai kawasan wisata sejarah yang implementatif.

\section{HASIL DAN DISKUSI}

\section{A. Menganalisis faktor-faktor yang mempengaruhi pengembangan kawasan heritage tourism di Kota Madiun}

Untuk mendapatkan faktor-faktor yang mempengaruhi pengembangan kawasan heritage tourism di Kota Madiun digunakan teknik analisis Delphi. Analisis Delphi merupakan suatu usaha untuk memperoleh consensus group yang dilakukan secara kontinu, sehingga didapatkan kesamaan opini dari setiap responden.

Tabel 1.

Responden Analisis Dhelpi

\begin{tabular}{ll}
\hline \multicolumn{1}{c}{ Nama Responden } & \multicolumn{1}{c}{ Pekerjaan } \\
\hline Bapak Budi Wibowo & Kepala Bidang pariwisata \\
Dyah Yuni Amd & Kasubid Perencanaan Umum dan \\
& Tata Ruang \\
Dwi Setyo & Kasi Pengawasan Bangunan Bid. Tata \\
Adjar dwijaya & Kota \\
\hline \hline
\end{tabular}

Dari beberapa variabel yang didapat dari tinjauan pustaka kemudian dianalisis sesuai dengan kondisi eksisting yang dibandingkan dengan literatur untuk memperoleh faktor. Disimpulkan bahwa faktor yang dapat mempengaruhi pengembangan kawasan heritage di kota Madiun yang di dapatkan dari hasil perbandingan antara variabel, teori dan kondisi eksisting, faktor pengembangan pariwisata heritage terpadu di Kota Madiun antara lain:

1. Adanya nilai kebudayaan pencak silat yang menjadi daya tarik terhadapa pengembangan kawasan heritage di Kota Madiun.
2. Tingginya tingkat kepedulian masyarakat terhadap sejarah setiap bangunan cagar budaya yang berada dekat pada lingkungan masing-masing.

3. Adanya kegiatan di setiap bangunan serta kawasan cagarbudaya menjadi penyebab kurang berkembangaknya kawasan cagar budaya

4. Adanya komunitas yang mewadahi kegiatan masyarakat lokal dalam upaya pelestarian cagar budaya di Kota Madiun.

5. Lemahnya kebijakan dan program pemerintah dalam mengembangkan kawasan heritage di Kota Madiun sebagai penyebab kurang perkembangan kawasan heritage.

6. Keterlibatan masyarakat dalam proses perencanaan kawasan heritage di Kota Madiun.

7. Pentingnya kemudahan akomodasi menuju lokasi kawasan heritage yang teintegrai.

8. Perlu adanya fasiltas dalam penunjang pariwisata sebagai pelayanan terhadapa pengunjung

- Eksplorasi Analisis Delphi Tahap I

Untuk melakukan eksplorasi pendapat responden, peneliti menggunakan kuesioner wawancara untuk membantu peneliti dalam proses wawancara. Penggunaan kuesioner wawancara tersebut memungkinkan responden untuk dapat mengungkapkan pendapatnya secara langsung dan lebih mendalam. Hal tersebut membantu peneliti dalam menentukan pendapat responden terhadap faktor yang mempengaruhi pengembangan

\begin{tabular}{|c|c|c|c|c|c|}
\hline \multirow{2}{*}{ No } & \multirow{2}{*}{ Faktor } & \multicolumn{4}{|c|}{ Responden } \\
\hline & & R1 & $\mathbf{R 2}$ & $\mathbf{R 3}$ & $\mathbf{R 4}$ \\
\hline 1 & $\begin{array}{l}\text { Adanya nilai kebudayaan pencak silat } \\
\text { yang menjadi daya tarik terhadapa } \\
\text { pengembangan kawasan heritage di } \\
\text { Kota Madiun. }\end{array}$ & TS & S & S & S \\
\hline 2 & $\begin{array}{l}\text { Tingginya tingkat kepedulian } \\
\text { masyarakat terhadap sejarah setiap } \\
\text { bangunan cagar budaya yang berada } \\
\text { dekat pada lingkungan masing-masing. }\end{array}$ & S & S & S & S \\
\hline 3 & $\begin{array}{l}\text { Tidak adanya kegiatan di setiap } \\
\text { bangunan serta kawasan cagarbudaya } \\
\text { menjadi penyebab rurang } \\
\text { berkembangnya kawasan cagar budaya }\end{array}$ & S & S & S & S \\
\hline 4 & $\begin{array}{l}\text { Adanya komunitas yang mewadahi } \\
\text { kegiatan masyarakat lokal dalam upaya } \\
\text { pelestarian cagar budaya di Kota } \\
\text { Madiun. }\end{array}$ & TS & S & S & S \\
\hline & $\begin{array}{l}\text { Lemahnya kebijakan dan program } \\
\text { pemerintah dalam mengembangkan }\end{array}$ & & & & \\
\hline 5 & $\begin{array}{l}\text { kawasan heritage di Kota Madiun } \\
\text { sebagai } \\
\text { perkembangan kawasan heritage. }\end{array}$ & $S$ & S & $S$ & S \\
\hline 6 & $\begin{array}{l}\text { Keterlibatan masyarakat dalam proses } \\
\text { perencanaan kawasan heritage di Kota } \\
\text { Madiun. }\end{array}$ & S & S & S & S \\
\hline 7 & $\begin{array}{l}\text { Pentingnya kemudahan akomodasi } \\
\text { menuju lokasi kawasan heritage yang } \\
\text { teintegrai. }\end{array}$ & S & S & S & S \\
\hline 8 & $\begin{array}{l}\text { Perlu adanya fasiltas dalam penunjang } \\
\text { pariwisata sebagai pelayanan terhadap } \\
\text { pengunjung }\end{array}$ & S & S & S & S \\
\hline
\end{tabular}

- Iterasi Tahap I Analisis Delphi

Pada tahap ini selanjutnya dilakukan pengulangan kuesioner setelah didapatkan hasil eksplorasi analisis Delphi. Iterasi dibutuhkan dikarenakan terdapat faktor yang belum mencapai konsensus dan penambahan faktor baru pada tahap eksplorasi 
sebelumnya dijadikan basis dalam penyusunan kuesioner wawancara di tahap iterasi.

\begin{tabular}{|c|c|c|c|c|c|}
\hline \multirow{2}{*}{ No } & \multirow{2}{*}{ Faktor } & \multicolumn{4}{|c|}{ "Responden } \\
\hline & & R1 & R2 & R3 & $\mathbf{R 4}$ \\
\hline 1 & $\begin{array}{l}\text { Adanya nilai kebudayaan pencak silat } \\
\text { yang menjadi daya tarik terhadapa } \\
\text { pengembangan kawasan heritage di Kota } \\
\text { Madiun. }\end{array}$ & S & S & S & S \\
\hline 2 & $\begin{array}{l}\text { Adanya komunitas yang mewadahi } \\
\text { kegiatan masyarakat lokal dalam upaya } \\
\text { pelestarian cagar budaya di Kota Madiun }\end{array}$ & $\mathrm{S}$ & S & $S$ & S \\
\hline 3 & $\begin{array}{l}\text { Adanya satu eventual bersama yang } \\
\text { melibatkan semua elemen yang terkait } \\
\text { dalam pengembangan pariwisata heritage }\end{array}$ & $\mathrm{S}$ & $\mathrm{S}$ & $\mathrm{S}$ & $S$ \\
\hline
\end{tabular}

Hasil analisis Delphi yang tertera diatas dan telah mencapai konsensus ini merupakan faktor yang mempengaruhi pengembangan kawasan heritage, faktor-faktor tersebut digunakan untuk merumuskan arahan integrasi kawasan heritage.

\begin{tabular}{ll}
\hline \hline No & \multicolumn{1}{c}{ Faktor } \\
\hline 1 & $\begin{array}{l}\text { Adanya nilai kebudayaan pencak silat yang menjadi daya tarik } \\
\text { terhadapa pengembangan kawasan heritage di Kota Madiun. }\end{array}$ \\
2 & $\begin{array}{l}\text { Tingginya tingkat kepedulian masyarakat terhadap sejarah setiap } \\
\text { bangunan cagar budaya yang berada dekat pada lingkungan } \\
\text { masing-masing. }\end{array}$ \\
3 & $\begin{array}{l}\text { Adanya kegiatan di setiap bangunan serta kawasan cagarbudaya } \\
\text { menjadi penyebab kurang berkembangnya kawasan cagar budaya }\end{array}$ \\
4 & $\begin{array}{l}\text { Adanya komunitas yang mewadahi kegiatan masyarakat lokal dalam } \\
\text { upaya pelestarian cagar budaya di Kota Madiun. }\end{array}$ \\
5 & $\begin{array}{l}\text { Lemahnya kebijakan dan program pemerintah dalam mengembangkan } \\
\text { kawasan heritage di Kota Madiun sebagai penyebab kurang } \\
\text { perkembangan kawasan heritage. }\end{array}$ \\
6 & $\begin{array}{l}\text { Keterlibatan masyarakat dalam proses perencanaan kawasan heritage di } \\
\text { Kota Madiun. }\end{array}$ \\
7 & $\begin{array}{l}\text { Pentingnya kemudahan akomodasi menuju lokasi kawasan heritage } \\
\text { yang teintegrai. }\end{array}$ \\
8 & $\begin{array}{l}\text { Perlu adanya fasiltas dalam penunjang pariwisata sebagai pelayanan } \\
\text { terhadap pengunjung } \\
\text { Adanya satu eventual bersama yang melibatkan semua elemen yang } \\
\text { terkait dalam pengembangan pariwisata heritage }\end{array}$ \\
\hline \hline
\end{tabular}

B. Perumusan arahan pengembangan Kawasan heritage terpadu di Kota Madiun

Dalam pengembangan kawasan wisata heritage, perlu dirumuskan arahan pengembangan

1. Area inti, mengandung daya tarik wisata yang menjadikan suatu kawasan sebagai daerah tujuan wisata.

2. Area pendukung langsung, merupakan pusat dari fasilitas pelayanan yang dibutuhkan oleh masyarakat dan juga wisatawan, seperti pertokoan, jasa pendukung pariwisata, dll.

3. Area pendukung tidak langsung, merupakan daerah sekitar yang masih terkena dampak dari kawasan wisata secara tidak langsung.

Dalam perumusan arahan pengembangan merupakan hasil analisis Delphi dan analisis Area pengembangan kegiatan wisata, dihasilkan arahan makro dan mikro kawasan. Arahan ini memiliki lingkup pengaplikasiannya tidak hanya berpengaruh untuk internal Kawasan cagar budaya kota Madiun, tetapi juga memiliki pengaruh untuk pengembangan wisata budaya yang berada di kota Madiun
Arahan makro yang dihasilkan berupa pembatasan area pengembangan kegiatan wisata yang jelas, yang dihasilkan dari analisis area pengembangan. Dalam arahan pengembangan untuk seluruh area baik cluster era Kolonial maupun era Mataraman pengembangan kegiatan wisata antara lain:

1. Peningkatan pemeliharaan bangunan cagar budaya, terutama bangunan yang belum terawat dengan baik, melalui perawatan agar tidak semakin rusak

2. Menjadikan Kawasan pada cluster era Kolonial sebagai kawasan wisata heritage yang bertemakan wisata sejarah peninggalan Belanda

3. Menjadikan Kawasan pada cluster era Mataraman sebagai kawasan wisata heritage yang bertemakan wisata sejarah persebaran islam di Kota Madiun

4. Menjadikan cluster era Kolonial dan era islam sebagai suatu integrasi pariwisata sehingga dpaat menarik wisatawan

5. Meningkatkan kesadaran masyarakat untuk menjaga dan melindungi cagar budaya dari kerusakan dengan cara mengadakan sosialisasi mengenai pentingnya pelestarian cagar budaya

6. Memberikan suporting untuk komunitas sejarah dalam upaya menjaga kelestarian serta sosialisasi pada masyarakat dtentang pentingnya menjaga cagar budaya untuk melestarikannya

7. Mengadakan kerjasama antara komunitas, pemerintah, dan masyarakat dalam pengelolaan bangunan cagar budaya

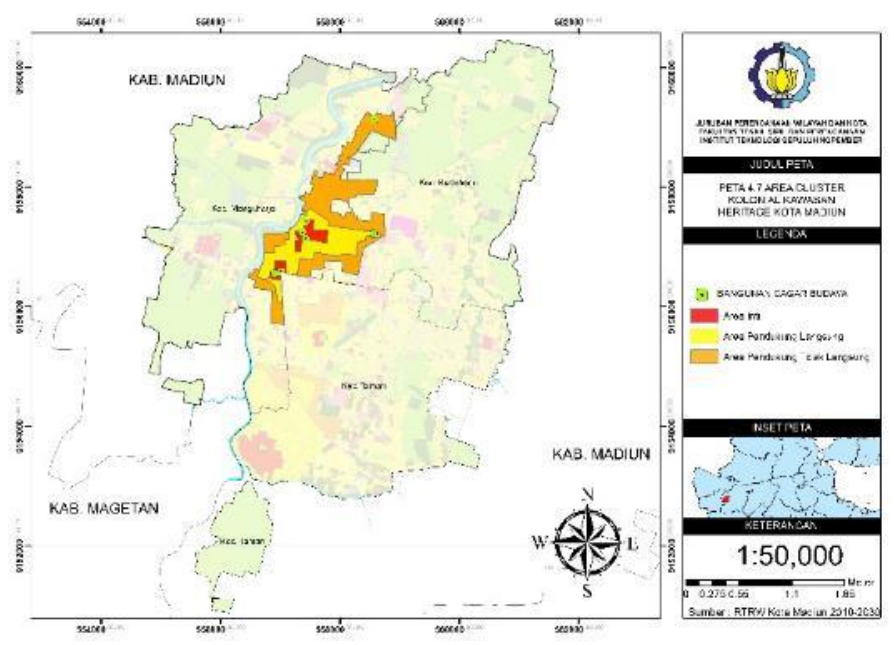

Gambar 1.Contoh Pembagian Area Cluster Kolonial

\section{Integrasi kawasan heritage cluster era Kolonial dan era Mataraman}

Kota Madiun pada dasarnya memiliki potensi pariwisata, baik dilihat dari peninggalan era Kolonial maupun era mataraman. Integrasi pariwisata penting dilakukan, agar terciptanya travel experience bagi wisatawan. Korelasi antara cluster era Kolonial yang berada pada koridor jalan pahlawan di integrasikan dengan cluster era mataram, yang dapat dilihat pada 2 situs masjid kuno di Kota Madiun (Masjid Taman \& Masjid Kuncen). Dimana nantinya Integrasi tercipta Karena adanya hubungan sejarah pada kedua Cluster tersebut.

1. Area inti pada setiap cluster menjadi pusat dari pengembangan wisata Heritage. Dilihat dari hasil Analisis 
potensi serta faktor pengembangan kawasan heritage, kawasan yang berada pada area inti menjadi daya tarik utama.

2. Memberikan prasaran dan sarana seperti lokasi parkir wisata, bus city tour untuk menuju lokasi wisata Heritage di Kota Madiun. Dimana bus city tour tersebut menuju ke titik bangunan cagar budaya dari kedua cluster.

3. Menempatkan Alun-Alun Kota Madiun sebagai meeting point serta menjadi pusat informasi terkait pariwisata heritage dan pariwisata budaya.

4. Menjadikan 2 padepokan pencak silat yang terletak di desa Sogaten dan Nambangan kidul sebagai kawasan wisata Budaya masyarakat Kota Madiun.

5. Memberikan sebuah suguhan pertunjukan di setiap padepokan pencak silat sebagai daya tarik dari Kota Madiun sebagai "Kampung Pendekar"

6. Menempatkan jalur heritage tourism d jalan protokol, serta menempatkan halte pemberhentian di sekitar kawasan cagar budaya. Dalam upaya memberikan fasilitas wisatawan menuju lokasi bangunan Cagar Budaya.

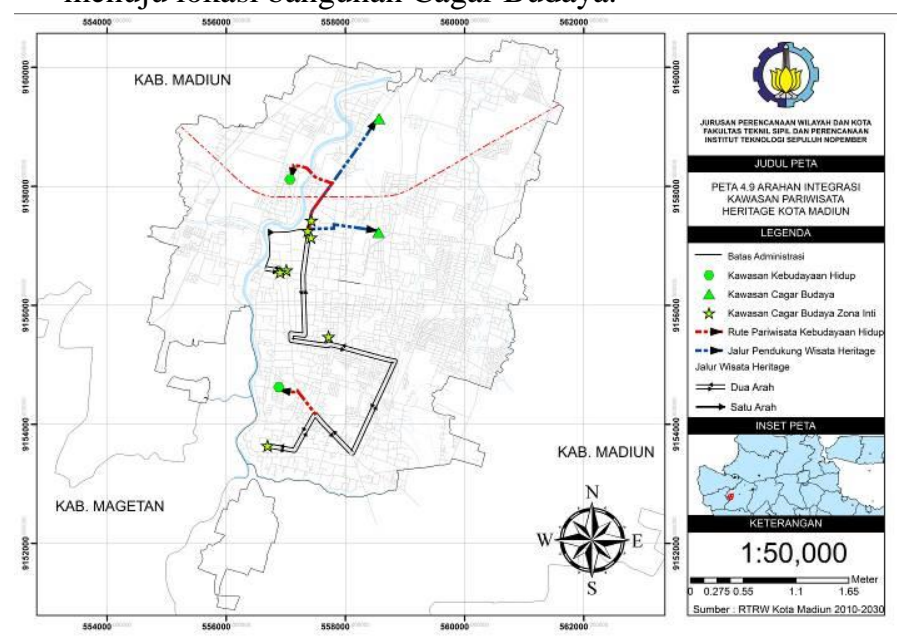

Gambar 2. Peta Jalur Pariwisata yang terintegrasi di kota Madiun

\section{KESIMPULAN}

Dari proses analisis yang telah dilakukan dapat di simpulkan bahwa Kota Madiun dapat di kembangkan menjadi kawasan pariwisata heritage. dimana kawasan heritage ota madiun di bedakan menjad 2 komunal berbeda yaitu cluster era kolonial dan cluster era mataraman. arahan pengembangan kawasan di bagi menjadi 2, yakni arahan makro dan mikro. Arahan pengembangan kawasan sebagai wisata sejarah secara makro adalah pembagian area pengembangan kegiatan wisata menjadi 3 area, antara lain area inti, area pendukung langsung, dan area pendukung tidak langsung.

Arahan Mikro yang di hasilkan serta disesuaikan dengan keadaan lokasi yang ada pada tiap area pengembangan kegiatan wisata yakni:

1. area inti: 1. memberikan guidelines tentang tata cara pemeliharaan dan renovasi; 2 . Membei rute wisata kawasan heritage; 3.membuat paket wisata sejarah; 4 . memanfaatkan pontensi BCB sebagai daya tarik; 5.pengadaan kegiatan eventual dalam upaya melestarikan budaya lokal; 6 .
Memberikan fasilitas pelayanan di setap kawasan pariwisata heritage.

2. area pendukung langsung: 1 . Memberian ruang parkir kendaraan wisatawan; 2. memberikan faslitas perdagangan dan jasa; 3. Mengadakan walk-in pada bangunan-bangunan cagar budaya; 4 . Pengembangan kegiatan ekonomi lokal yang berhubungan dengan kegiatan pariwisata berupa penjualan souvenir khas madiun; 5. Pengembangan makanan khas Kota Madiun seperti sambel pecel, brem, lempeng dengan memberikan sentra wisata oleh-oleh untuk wisatawan yang berkunjung: 6 . Pengembangan kegiatan wisata budaya di kedua padepokan pusat perguruan pencak silat terbesar di indonesia sebagai penunjang wisata heritage.

3. area pendukung tidak langsung: 1. Memberikan information board di depan bangunan tersebut mengenai sejarah bangunan; 2. Pemberian ruang untuk parkir terpusat untuk sarana pendukung pariwisata

\section{DAFTAR PUSTAKA}

[1] O. Yoeti, Pengantar Ilmu Pariwisata. Bandung: Angkasa, 1996.

[2] Sugiyono, Metode Penelitian Pendidikan: Pendekatan Kuantitatif, Kualitatif dan $R \& D$. Bandung: Alfabeta, 2006.

[3] I. K. Suwena, Pengetahuan Dasar Ilmu Pariwisata. Denpasar: Udayana Press, 2010.

[4] Rencana Tata Ruang Kawasan Strategis Kota Madiun. 2010.

[5] I. G. B. R. Utama, "Pengembangan Wisata Kota sebagai Pariwisata Masa Depan Indonesia," 2013. [Online]. Available: www.academia.edu .

[6] I. G. Pitana, Sosiologi Pariwisata, Kajian Sosiologis Terhadap Struktur, Sistem, dan Dampak-Dampak Pariwisata. Yogyakarta: Andi Offset, 2005. 